\title{
Mentorship - Propitious Methodology to Improve Low Performers
}

\author{
Desi Vidya Sripad, Gautam Nichenametla, Naga Guhan V*, Joy A Ghoshal, Amudharaj Dharmalingam, \\ Desi Vidya Sripad, Additional Professor \& Head, Department of Biochemistry, All India Institute of Medical Sciences, Mangalagiri, TS, India. \\ Gautam Nichenametla, Senior Resident, Department of Biochemistry, All India Institute of Medical Sciences, Mangalagiri, TS, India. \\ Naga Guhan V*, Assistant Professor, Department of Biochemistry, All India Institute of Medical Sciences, Mangalagiri, TS, India. \\ Joy A Ghoshal, Dean, Professor \& Head, Department of Anatomy, All India Institute of Medical Sciences, Mangalagiri, TS, India. \\ Amudharaj Dharmalingam, Associate Professor, Department of Physiology, All India Institute of Medical Sciences, Mangalagiri, TS, India. \\ *Corresponding author's E-mail: guhan@aiimsmangalagiri.edu.in
}

Received: 22-05-2021; Revised: 18-07-2021; Accepted: 26-07-2021; Published on: 15-08-2021.

\section{ABSTRACT}

Mentorship program have a wide array of benefits which imparts an important role in reversing the decline of academics and helps in understanding the challenges encountered. The main objectives of the MP are 1) To address the student's problematic areas and identify sectors where they need more support. 2) To provide immediate support network to the Low performers and establish small group mentoring program which was based on performance basis. A total of 50 students and 28 faculty were involved in the study. All the 50 students were allotted mentor, in a lottery basis picked by the students, with the mentor to mentee ratio of 1:2. The marks obtained in Mid Term 1 exam was taken as baseline and compared with subsequent exam marks to identify the effectiveness of mentorship program. Further, at the end of terminal exam, 13 students were identified as low performers and were given an extra focused care other than regular mentoring. At the end of the 1st year MBBS, a preformed questionnaire with four Likert scale was taken to understand the effectiveness of mentorship. The marks were expressed in mean \pm SD. The marks between the exams were compared using Paired t Test. SPSS 26.0 was used for all statistical procedures. Among the low performers, the comparative improvement in the marks between Terminal and Mid Term II was $18 \%$ in Anatomy $(p<0.000)$, $9 \%$ in Physiology $(p<0.005)$ and $8 \%$ in Biochemistry $(p<0.01)$. Further the comparative improvement in the marks between Mid Term II and Final Professional exams was $5 \%$ in Anatomy $(p<0.029), 5 \%$ in Physiology and $11 \%$ in Biochemistry $(p<0.001)$. In addition, analysis of students feedback revealed that $38 \%$ of the students have agreed and $54 \%$ of them have strongly agreed that mentorship program was effective and beneficial to them. Mentorship Program should be a part of the academic plan and should be implemented in all medical Colleges to bring out efficient Doctors and prevent dropouts of medicos. Students with effective mentors as role models will imbibe the qualities and attributes of their mentor and in turn become good mentors and thus perpetuate the cycle.

Keywords: Mentorship, Impact on Academics, Low Performers, Present trend.

QUICK RESPONSE CODE $\rightarrow$

DOI:

10.47583/ijpsrr.2021.v69i02.024

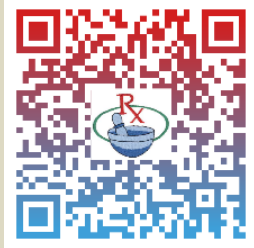

DOI link: http://dx.doi.org/10.47583/ijpsrr.2021.v69i02.024

\section{INTRODUCTION}

M entorship program (MP) in medical schools, have a wide array of benefits. The new beginners are more vulnerable to the vast challenges of coping up with the Medical course. Mentorship program is known in offering support to the new entrants ${ }^{1}$. It is one of the best approaches towards a student, in understanding their starting problems and to cope up with the tough curriculum. It helps in an overall development of a medical student and thus make them emerge as an efficient Doctor.

According to a study by Zerzan et al, Mentorship program provide emotional and career support, facilitate insight, managing up time, building confidence and establishing a good communicative network system. ${ }^{2}$ A study conducted by Scheckler et al at Wisconsin Medical University states that for incoming student the support extended by assigning a single mentor has an immense effective role. ${ }^{3}$ Though mentoring programs are carried worldwide, according to Frei et al, only after 1990's the MP was started for medical students. ${ }^{4}$ Mentoring is cost free strategy based on a personal and professional context , unlike coaching and counselling. It is a dynamic, collaborative and reciprocal relationship focused on a Mentee personal and professional development. ${ }^{2}$

Although there are many studies by Buddeberg Fisher and Ramanan R stating that mentorship program is one of the most important key determinants for a successful academic performance in medicine, MP has not been implemented regularly in most of the Medical Colleges. ${ }^{5,6}$ The five important key elements of mentoring are as follows 1 . Should help the mentee to achieve short-and long-term goals. 2 . Should include role modeling and help with career development. 3. Both mentee and mentor should benefit from the relationship. 4. Relationships should involve direct interaction between mentor and 
mentee. 5. Mentors should be more experienced when compared with the mentee. ${ }^{7}$

In view of the increasing awareness of the importance of Mentoring, Mentoring programs are now slowly getting established at Medical Schools worldwide. Taking this into consideration we designed our Mentoring program right from the inception of the institute to support the medical entrants right from the first year. The highlights of our MP will in turn guide the institute, mentors and mentees in the future design and delivery of effective academic learning, relearning, lifelong learning and self-directed learning.

The main aim and objective of our mentorship program is to give structured and directive guidance, to all the students and identify the low performers. The main objectives of the MP are 1) To address the student's problematic areas and identify sectors where they need more support. 2) To provide immediate support network to the Low performers and establish small group mentoring program which was based on performance basis.

\section{MATERIALS AND METHODS}

In this program, the following three persons had the major core responsibilities - The Leader of Mentorship program, the Mentor and the Mentee and each one of them had a specific role.

1. Leader played a major role in designing \& executing the program, following up the trend, monitoring \& intervening wherever necessary, and finally working to get the best outcome.

2. Mentor: An Experienced and trusted advisor had a crucial role as a first contact person with the student. Mentor imparted an important role in reversing the decline of academics, apart from that they also helped in understanding the challenges encountered assisting for potential benefit and future implications for mentees

3. Mentee: The student who had the responsibility of sharing the difficulties encountered by him/her in academics, if any health issue, peer issues or any other area of concern.

The mentorship program (MP) was carried out for the first MBBS students of AlIMS Mangalagiri. It was headed by the Associate Dean of Academic and exams. The Program was designed, executed and monitored by the Associate Dean. An induction program was conducted for Mentors at the starting of the academic year to explain their roles and responsibilities towards the MP. Their willingness and consent to be a part of the MP was taken. All the Faculty of the First MBBS Anatomy, Physiology, Biochemistry and Community and Family medicine (CFM) were involved in the Program .CFM faculty were also involved as CFM was taught from the first year according to the AlIMS curriculum keeping in mind the early exposure to the students. To prevent bias the HOD of these four departments were excluded from the MP.
All the 50 students of First MBBS were the subjects. All the 50 students were allotted mentor, in a lottery basis picked by the students. As we had 28 Faculty members almost the ratio was 1 mentor for 2 students, which was an added benefit for our MP. A mentorship form was designed which contained the following details- his/her schooling, cocurricular, parents, siblings, peer-relationship, areas \& interest, health issues if any are taken. A mentorship card was designed which included 4 main parts:

1) Personal data of the student: Name, DOB/Age, Gender, Email, Personal Mobile number and contact number of parents and local guardian. Name of two best friends with their contact numbers

2) Mentee Confidential report: Personal problems, health issues, addictions, family support, any other Counselling.

3) Mentee Year Planner: Planned update, Actual update, Mentee signature, Mentor signature.

4) Mentee Progress chart: A sheet indicating the attendance and marks of the student in different subjects. (Beginning from October to July)

The mentorship sessions were scheduled every Wednesday between 4:30 to 5:30pm where the students should meet his/her mentor one on one basis. The factors influencing their academic performance like adjusting with food habits, peer pressure and health factors were evaluated with sincere efforts by the Mentor and were given solutions. All personal data expressed by the students were kept confidential.

Mentorship event was observed after every major test and the results were compiled and analyzed by the Associate Dean of Academic \& exams and was submitted to Dean and Director of the Institute through proper channel. Finally at the end of final professional exam, Students feedback were collected to assess whether mentorship program helped him/her in improving the 1) Analytical ability 2) Peer pressure handling 3) Time management and 4) Overall performance using a Likert scale based valid questionnaire. The marks were expressed in mean \pm SD. The marks between the exams were compared using Paired T Test. SPSS 26.0 was used for all statistical procedures

\section{RESULTS}

The marks obtained in Mid Term 1 exam was taken as baseline and compared with terminal exam marks (which was conducted two months after Midterm 1) to identify the effectiveness of mentorship program. (Table 1). There was no significant improvement in most of the subjects. Then the students were divided into two groups based on their scores in Mid term1 exam - Group A - 37 students with > 35\% marks: Group B -13 students with < 35\% marks. When their marks were compared within the group, there was a significant improvement in Group $A$ in terminal exam but not in Group B(Table 2), which implied 
that low performers needed extra care than the regular mentoring. So, a meeting with mentors of low performers was organized and mentors were instructed to guide them in relation to understanding the subjects, management of time, coping up with the new circumstances and situations identifying the different chapters. They were followed up weekly thrice and they were advised on time management and regular assignments were given, which were evaluated by the respective Mentor with the support of faculties from respective departments and were given advice on how to present and improve their writing presentations.
Thereafter every major test like midterm 2 \& Final exam marks were compared with their previous performance in both the groups. There was a significant improvement in marks in both the groups. (Table $3 \& 4$ ). The mean difference of marks between the groups were reduced to more than $40 \%$ at the end of academic year than compared to the terminal exam. This improvement in students' academic performance can be attributed to our mentorship program which was further supported by the students' feedback results. (Table 5)

Table 1: Comparison of marks between Mid term 1 \& Terminal Examination

\begin{tabular}{|c|c|c|c|c|}
\hline SUBJECT & Midterm $\mathbf{1}($ mean \pm SD) & Terminal (mean \pm SD) & Mean Difference & P value \\
\hline Anatomy & $43.70 \pm 12.845$ & $47.18 \pm 12.702$ & -3.480 & 0.176 \\
\hline Physiology & $44.22 \pm 10.251$ & $53.64 \pm 12.417$ & -9.420 & 0.000 \\
\hline Biochemistry & $49.02 \pm 12.255$ & $45.70 \pm 11.055$ & 3.320 & 0.158 \\
\hline
\end{tabular}

Table 2: Comparison of marks within the group between Midterm 1 \& Terminal Examination

\begin{tabular}{|c|c|c|c|c|c|}
\hline SUBJECT & GROUPS & Midterm 1 (mean \pm SD) & Terminal (mean \pm SD) & Mean Difference & P value \\
\hline \multirow{2}{*}{ Anatomy } & A $(n=37)$ & $48.62 \pm 10.615$ & $51.7 \pm 11.075$ & -3.081 & 0.023 \\
\hline & B $(n=13)$ & $29.69 \pm 6.957$ & $34.31 \pm 6.945$ & -4.615 & 0.71 \\
\hline \multirow{2}{*}{ Physiology } & A $(n=37)$ & $48.19 \pm 8.286$ & $57.59 \pm 10.725$ & -9.405 & 0.000 \\
\hline & B $(n=13)$ & $32.92 \pm 6.02$ & $42.38 \pm 9.954$ & -9.462 & 0.016 \\
\hline Biochemistry & A $(n=37)$ & $53.24 \pm 9.937$ & $50.24 \pm 8.532$ & +3 & 0.036 \\
\hline & B $(n=13)$ & $37 \pm 10.271$ & $32.77 \pm 5.988$ & +4.231 & 0.114 \\
\hline
\end{tabular}

Table 3: Comparison of marks between Terminal \& Mid Term 2 Examination

\begin{tabular}{|c|c|c|c|c|c|}
\hline Subject & Groups & Terminal (mean \pm SD) & $\begin{array}{c}\text { Mid Term Exam 2 } \\
\text { (mean } \pm \text { SD) }\end{array}$ & $\begin{array}{c}\text { Mean } \\
\text { Difference }\end{array}$ & P value \\
\hline Anatomy & A $(n=37)$ & $51.7 \pm 11.075$ & $61.49 \pm 12.103$ & -9.784 & 0.000 \\
\hline B $(n=13)$ & $34.31 \pm 6.945$ & $52.31 \pm 8.674$ & -18 & 0.000 \\
\hline Physiology & A $(n=37)$ & $57.59 \pm 10.725$ & $65.35 \pm 11.074$ & -7.757 & 0.000 \\
\hline Biochemistry & B $(n=13)$ & $42.38 \pm 9.954$ & $51.69 \pm 11.679$ & -9.308 & 0.005 \\
\hline & A $(n=37)$ & $50.24 \pm 8.532$ & $52.78 \pm 9.178$ & -2.541 & 0.099 \\
\hline
\end{tabular}

Table 4: Comparison of marks between Mid Term 2 \& Final Examination

\begin{tabular}{|c|c|c|c|c|c|}
\hline Subject & Groups & $\begin{array}{l}\text { Mid Term Exam } 2 \\
(\text { mean } \pm \text { SD) }\end{array}$ & Final Exam (mean $\pm S D)$ & Mean Difference & $P$ value \\
\hline \multirow{2}{*}{ Anatomy } & $A(n=37)$ & $61.49 \pm 12.103$ & $68.65 \pm 6.55$ & -7.162 & 0.000 \\
\hline & $B(n=13)$ & $52.31 \pm 8.674$ & $57.77 \pm 9.112$ & -5.462 & 0.029 \\
\hline \multirow{2}{*}{ Physiology } & $A(n=37)$ & $65.35 \pm 11.074$ & $71 \pm 7.524$ & -5.649 & 0.001 \\
\hline & $B(n=13)$ & $51.69 \pm 11.679$ & $56.54 \pm 9.580$ & -4.846 & 0.104 \\
\hline \multirow{2}{*}{ Biochemistry } & $A(n=37)$ & $52.78 \pm 9.178$ & $62.41 \pm 5.444$ & -9.622 & 0.000 \\
\hline & $B(n=13)$ & $41 \pm 9.247$ & $52.69 \pm 10.523$ & -11.692 & 0.001 \\
\hline
\end{tabular}


Table 5: Students feedback about mentorship program

\begin{tabular}{|c|c|c|c|c|c|}
\hline & Questions & $\begin{array}{c}\text { Strongly } \\
\text { Disagree (1) }\end{array}$ & Disagree (2) & Agree (3) & Strongly Agree (4) \\
\hline 1 & My mentor was accessible and available & $2 \%$ & $12 \%$ & $36 \%$ & $50 \%$ \\
\hline 2 & My mentor communicated regularly with me & $4 \%$ & $14 \%$ & $42 \%$ & $40 \%$ \\
\hline 3 & My mentor assisted me with my career queries & $0 \%$ & $4 \%$ & $52 \%$ & $44 \%$ \\
\hline 4 & $\begin{array}{l}\text { Mentorship program assisted me in improving my } \\
\text { course work performance }\end{array}$ & $2 \%$ & $14 \%$ & $42 \%$ & $42 \%$ \\
\hline 5 & $\begin{array}{l}\text { Mentorship program assisted me with my } \\
\text { understanding of the academic routes to achieve my } \\
\text { current career goals }\end{array}$ & $0 \%$ & $16 \%$ & $50 \%$ & $34 \%$ \\
\hline 6 & $\begin{array}{l}\text { My mentor demonstrated a reasonable } \\
\text { interest/concern towards me }\end{array}$ & $4 \%$ & $12 \%$ & $44 \%$ & $40 \%$ \\
\hline 7 & $\begin{array}{l}\text { My mentor's behaviour and attitude generally is an } \\
\text { example of professionalism }\end{array}$ & $0 \%$ & $2 \%$ & $44 \%$ & $50 \%$ \\
\hline 8 & $\begin{array}{l}\text { I learned at least one important lesson about my career } \\
\text { or professionalism from my mentor. }\end{array}$ & $0 \%$ & $8 \%$ & $38 \%$ & $54 \%$ \\
\hline 9 & $\begin{array}{l}\text { I recommend mentorship program for future } \\
\text { professional or personal development activities. }\end{array}$ & $0 \%$ & $2 \%$ & $24 \%$ & $74 \%$ \\
\hline 10 & $\begin{array}{l}\text { Overall, mentorship program was effective and } \\
\text { beneficial to me. }\end{array}$ & $2 \%$ & $6 \%$ & $38 \%$ & $54 \%$ \\
\hline 11 & $\begin{array}{l}\text { I am willing to be a part of mentorship program for my } \\
\text { juniors }\end{array}$ & $10 \%$ & $12 \%$ & $26 \%$ & $52 \%$ \\
\hline
\end{tabular}

\section{DISCUSSION}

Mentorship has been defined as "a dynamic, reciprocal relationship in a work environment between an advanced career incumbent (mentor) and a beginner (mentee), aimed at the development of both." ${ }^{8}$ It offers a mentee with various strategies for self-improvement, helps them in goal setting and achieving the same. The benefits for mentors are, it ensures that they remain updated and also increases the credibility of the self as well as the organization. ${ }^{9} \mathrm{MP}$ is the need of the hour to impart and maintain professionalism and ethics in the medical profession world over. Greater emphasis is now being placed on structured outcome-oriented mentorship in the Western countries, as it promotes the acquisition of desirable competencies. ${ }^{10}$ Hence, mentoring and nurturing by advanced learners and facilitators has to be carried out within the organizational framework of every medical institution.

In our study, mentorship program was structured in a way that students' problematic areas were identified and immediate support and guidance were offered to all students. First year MBBS students, the beginners of the robust profession, faced lot of problems like time management, stress management, adjustment issues etc. Mentors played a major role in guiding the MBBS students in tackling all these problems and helped them in appropriate grooving into the profession. Our MP was not only focusing on academic performance, it also emphasized on other factors like initial adjustments problems regarding place, food and numerous health issues, which influence the overall grooming of a Medico into a professional Doctor.

Despite these efforts from our team of mentors, there was no improvement observed in the academic performance of certain students in the initial days. At the end of terminal exam, these students were identified as low performers and were given an extra focused care other than regular mentoring. Thirteen students had obtained less than $35 \%$ in Anatomy, Physiology and Biochemistry, and they were grouped as low performers. They were followed up weekly thrice and were given regular assignments, which were evaluated by the respective Mentor with the support of faculties from respective departments and were given advice on time management and how to present and improve their writing presentations. This way low performers were lined up and put in a system which helped them in coping up and improving. The improvement was evident from their marks of the exams which were conducted thereafter.

Among the low performers, the comparative improvement in the marks between Terminal and Mid Term II was $18 \%$ in Anatomy $(p<0.000), 9 \%$ in Physiology $(p<0.005)$ and $8 \%$ in Biochemistry $(p<0.01)$. Further the comparative improvement in the marks between Mid Term II and Final Professional exams was $5 \%$ in Anatomy $(p<0.029), 5 \%$ in Physiology and $11 \%$ in Biochemistry $(p<0.001)$. Among the 13 students, who had secured $<35 \%$ marks in the initial days, 11 students have passed ( $>50 \%$ marks) the final exam which could not have been achieved without the effective and focused care through mentorship program. Apart from 
these quantitative data, the effectiveness of mentorship program was further reinforced by students' feedback. $38 \%$ of the students have agreed and $54 \%$ of them have strongly agreed that mentorship program was effective and beneficial to them. Further almost $98 \%$ of them have recommended to continue the program in the future for professional and personal development. They had also shown interest $(78 \%$ of students) to be a part of mentorship program for their juniors.

The effectiveness and benefits of mentorship program were supported by few other previous studies too. Amy Hawkins et al, concluded in their study that the key benefits of mentoring for students were improved confidence, academic support, increased enjoyment and sense of belonging. ${ }^{11}$ Karuna $P$ et al, in their study, recommended that $A$ well-planned and goal-oriented mentoring programme benefits the mentees in building their academic career as well as personal development. ${ }^{12}$ The Mentorship Programme in medical college has been shown to be an effective channel for addressing and minimising the performance gaps in students. ${ }^{9}$ It is a structured, goal driven finite process that enables proper acquisition of clinical skills in graduates as well as post graduates. ${ }^{14}$ Especially, in first year students, it helps in a positive overall performance of the students and plays an important role to lay a strong foundation for Medical Profession.

\section{CONCLUSION}

Mentorship Program should be a part of the Academic plan and should be implemented in all Medical Colleges to bring out efficient Doctors and prevent dropouts of Medicos. We recommend that all medical institutions have to start or rejuvenate mentorship programs in various stages of medical graduate and post graduate program in India. Students with effective Mentors as role models will imbibe the qualities and attributes of their mentor and in turn become good mentors (peer mentors) and thus perpetuate the cycle.

\section{Limitations}

The feedback from mentors regarding the overall process and about their individual mentees performance was not collected. This reflection would have given more inputs in improving and redesigning the overall program in the future.

Acknowledgements: We would like to acknowledge the sincere and meticulous effort of the faculties of Anatomy, Physiology, Biochemistry and CFM department for the success of mentorship program. We would also thank our Director and Dean for their constant support.

\section{Practice Points}

- All the 50 students were allotted mentor, in a lottery basis picked by the students, with the mentor to mentee ratio of $1: 2$
- The factors influencing their academic performance like adjusting with food habits, peer pressure and health factors were evaluated with sincere efforts by the Mentor and were given solutions.

- A statistically significant academic improvement was observed in all the students in due course of mentorship program

- Students feedback revealed that $38 \%$ of the students have agreed and $54 \%$ of them have strongly agreed that mentorship program was effective and beneficial to them

- Mentorship Program should be a part of the Academic plan and should be implemented in all Medical Colleges to bring out efficient Doctors and prevent dropouts of Medicos

\section{REFERENCES}

1. Kukreja S, Chhabra N, Kaur A, Arora R, Singh T. Introducing mentoring to 1st-year medical students of a private medical college in North India: A pilot study. International Journal of Applied and Basic Medical Research. 2017; 7(Suppl 1): 567 10.4103/ijabmr.IJABMR_160_17

2. Judy $\mathrm{T}$ Zerzan, Rachel Hess, Ellen Schur, Russell $\mathrm{S}$ Phillips, Nancy Rigotti. Making the Most of Mentors: A Guide for Mentees. Acad Med 2009 Jan; 84(1): 1404.

3. William E Scheckler, Gordon Tuffli, Don Schalch, Archie MacKinney, Edward Ehrlich. The Class Mentor Program at the University of Wisconsin Medical School: A Unique and Valuable Asset for Students and Faculty. WMJ. 2004; 103(7): 46-50.

4. Frei E, Stamm M, Buddeberg-Fischer B. Mentoring programs for medical students - a review of the PubMed literature 2000-2008. BMC medical education. 2010; 10: 32.

5. Buddeberg-Fischer B, Herta KD. Formal mentoring programmes for medical students and doctors--a review of the Medline literature. Med Teach. 2006; 28(3): 248-257.

6. Ramanan RA, Taylor WC, Davis RB, Phillips RS. Mentoring matters. Mentoring and career preparation in internal medicine residency training. J Gen Intern Med. 2006; 21(4): 340-345.

7. Ramanan R, Phillips R, Davis R, Silen W, Reede J: Mentoring in medicine: keys to satisfaction. Am J Med. 2002, 112 (4): 336-341.

8. Sambunjak D, Straus S E, Marusić A. Mentoring in academic medicine: a systematic review. JAMA. 2006 Sep 6; 296(9): 1103-15.

9. Dalgaty $F$, Guthrie $G$, Walker $H$, et al. The value of mentorship in medical education. Clin Teach. 2017; 14(2): 124-8. 
10. Frei E., Stamm M, Buddeberg-Fischer B. Mentoring programs for medical students -a review of the PubMed literature 2000 - 2008. BMC Med Educ 2010;10:32. http://doi. org/10.1186/1472-6920-1032

11. Amy Hawkins, Kevin Jones, Andrew Stanton. A Mentorship Programme for Final-Year Students. Clin Teach 2014 Aug; 11(5): 345-9.
12. Karuna Sree P., Rajya Lakshmi N., Venkata Rao Y., Archana A.D, Shruti Mohanty. Mentoring in Medical Education: Impact on the Undergraduate Students. Journal of Research in Medical Education \& Ethics; March 2018; Vol. 8, No. 1: pp-69-73.

13. Awasthi S. Mentoring in medical education: A neglected essentiality. MJMS. 2017; 2(1): 5-7.

Source of Support: The author(s) received no financial support for the research, authorship, and/or publication of this article.

Conflict of Interest: The author(s) declared no potential conflicts of interest with respect to the research, authorship, and/or publication of this article.

For any question relates to this article, please reach us at: editor@globalresearchonline.net New manuscripts for publication can be submitted at: submit@globalresearchonline.net and submit_ijpsrr@rediffmail.com 